\section{(2) OPEN ACCESS}

\title{
Quality evaluation and future priorities for delivering acute myocardial infarction care in Sri Lanka
}

\author{
Walithotage Gotabhaya Ranasinghe, ${ }_{1}^{1}$ Abi Beane (D) , 2,3,4,5 \\ Thamal Dasitha Palligoda Vithanage, ${ }_{1}^{1}$ Gamage Dona Dilanthi Priyadarshani, ${ }^{2,3}$ \\ Don Dhanushka Eranga Colombage, ${ }^{1}$ Chandrike Janminda Ponnamperuma, ${ }^{1}$ \\ Suneth Karunarathne, ${ }_{1}^{1}$ Constance Schultsz, ${ }^{5}$ Arjen M Dondorp, ${ }_{1}^{2,4}$ Rashan Haniffa ${ }^{2,3,6}$
}

\begin{abstract}
- Additional material is published online only. To view please visit the journal online (http://dx.doi.org/10.1136/ heartjnl-2019-315396)

${ }^{1}$ Institute of Cardiology, National Hospital Sri Lanka, Colombo, Sri Lanka

${ }^{2}$ Department of Critical care and Malaria, Mahidol Oxford Tropical Medicine Research Unit, Bangkok, Thailand

${ }^{3}$ Network for Improving Critical Care System and Training,

Colombo, Sri Lanka

${ }^{4}$ Nuffield Department of

Medicine, University of Oxford,

Oxford, UK

${ }^{5}$ Department of Global Health

- AIGHD Amsterdam UMC, University of Amsterdam,

Amsterdam, The Netherlands

${ }^{6}$ Internal Medicine, University

College London, London, United

Kingdom
\end{abstract}

Correspondence to

Abi Beane, Mahidol Oxford

Tropical Medicine Research Unit,

Bangkok 10400, Thailand;

abi@nicslk.com

WGR and $A B$ contributed equally.

$A B$ and $W G R$ are joint first authors.

Received 20 May 2019 Revised 25 August 2019 Accepted 9 September 2019 Published Online First 16 December 2019

Check for updates

(C) Author(s) (or their employer(s)) 2020. Re-use permitted under CC BY-NC. No commercial re-use. See rights and permissions. Published by BMJ.

To cite: Ranasinghe WG Beane $A$, Vithanage TDP, et al. Heart 2020;106:603-608.

\section{ABSTRACT}

Aim This study evaluates the quality of care for patients admitted with acute myocardial infarction (AMI) in a tertiary hospital in Colombo using the European Society of Cardiology Quality of Care Working Group's guidelines (2017).

Methods A recently implemented electronic AMI registry $m$-Health tool was used for prospective data collection. Each patient was assessed for eligibility for each of the six domains of quality. Global Registry of Acute Coronary Events Risk Model for predicted probability of mortality, and scores for risk of bleeding complications (CRUSADE) and severity of heart failure (Killip classification) were calculated as per published guidelines. A composite measure of quality was derived from compliance with the six domains. Patients were followed up via telephone at 30 days following discharge to evaluate outcome and satisfaction. Organisational information was assessed by administrative review and interview.

Results Between March 2017 and April 2018, 934 patients with AMI presented to the cardiology department. The majority of patients $(90.4 \%)$ presented with features of ST-elevation myocardial infarction (STEMI). Mean (SD) overall compliance with the composite quality indicator (CQI) was 44\% (0.07). Compliance of $\geq 50 \%$ to the CQI was achieved in $9.8 \%$ of STEMI patients. The highest compliance was observed for antithrombotics during hospitalisation (79.1\%) and continuous measure of patient satisfaction (76.1\%). The lowest compliance was for organisational structure and care processes (22.4\%).

Conclusion This study reports a registry-based continuous evaluation of the quality of AMI care from a low and middle-income country. Priorities for improvement include improved referral, and networking of primary and secondary health facilities with the percutaneous coronary intervention centre.

\section{INTRODUCTION}

Poor quality of healthcare is an important cause of excess mortality in low and middle-income countries (LMICs) exceeding in importance unavailability and inaccessibility of care. ${ }^{1}$ Cardiovascular disease is a major cause of death globally, and has overtaken infectious diseases as the primary cause of death in South Asia. Delivery of high-quality cardiovascular disease care, as with other non-communicable diseases, places a significant burden on primary, secondary, tertiary and supportive health services. ${ }^{1-3}$ Addressing quality of care in patients with acute myocardial infarction (AMI) in LMICs could thus have major impact on patient outcomes.

In Sri Lanka, government-led health services have invested heavily in tertiary services for management of AMI including catheterisation laboratories, imaging facilities, pharmacology and laboratory services. These facilities are essential for both immediate and intermediate management of patients presenting with AMI. ${ }^{4}$ However, there remains little known of the quality of in-hospital care processes and outcomes extending beyond the hospital setting. Furthermore, patient-centred outcomes - satisfaction, quality of recovery and information on postintervention burden of symptoms remain largely absent. ${ }^{1}$

Identifying gaps in existing care and the priorities for improvement requires detailed information regarding the organisational structures and process of care that the patient experiences throughout their treatment and into recovery. Continuous surveillance systems, such as those implemented in high-income countries are ideally suited to capture the level of granular data needed to evaluate quality of care for AMI and to help stakeholders identify priorities for improvement. ${ }^{67}$ Digital surveillance systems capable of replicable and continuous evaluation of care that can be embedded within healthcare delivery remain notably absent in many LMICs. However, recent efforts have shown that such systems are both feasible and can help guide priorities for care improvement. ${ }^{8-10}$

\section{Aim}

This paper evaluates the quality of care for patients admitted with AMI in a large tertiary hospital in Colombo, Sri Lanka.

\section{METHODS}

\section{Selection of quality indicators (QIs)}

The European Society of Cardiology (ESC 2017) Quality of Care Working Group's ${ }^{11}$ consensus on quality was selected as the framework for evaluation. These guidelines were designed to provide a broad understanding of the quality of AMI care throughout the patients treatment path and include 


\begin{tabular}{|c|c|c|c|c|}
\hline Domains & Total population & Eligible population & Availability (\%) & Compliance (\%) SE \\
\hline 1. Centre organisation and system level structures of AMI care & - & - & - & - \\
\hline 2. Reperfusion invasive strategy & & & & 22.4 \\
\hline QI 2.1. For patients treated with fibrinolysis: $<30 \mathrm{~min}$ from diagnosis to the needle. & 844 & 53 & $39(73.6)$ & $10(25.6) 0.07$ \\
\hline $\begin{array}{l}\text { QI 2.2. For patients treated with primary } \mathrm{PCl} \text { and admitted: }<60 \mathrm{~min} \text { from door to balloon } \\
\text { time. }\end{array}$ & 844 & 442 & $309(69.9)$ & $45(14.6) 0.02$ \\
\hline $\begin{array}{l}\text { QI 2.3. The proportion of patients with NSTEMI, and no contraindication, who receive } \\
\text { coronary angiography within } 72 \text { hours after admission. }\end{array}$ & 90 & 90 & $90(100)$ & $27(30.0) 0.05$ \\
\hline 3. In-hospital risk assessment NSTEMI & & & & 50.6 \\
\hline $\begin{array}{l}\text { QI 3.1. The proportion of patients with NSTEMI who have ischaemic risk assessment using } \\
\text { the GRACE risk score }\end{array}$ & 90 & 90 & $90(100)$ & $71(78.9) 0.04$ \\
\hline Mean GRACE score & & & & $120.4(S D=39.9)$ \\
\hline Median GRACE score & & & & 114 \\
\hline Mean probability of death in hospital & & & & $1 \%-3 \%$ \\
\hline $\begin{array}{l}\text { QI 3.2. Proportion of patients admitted with STEMI or NSTEMI bleeding risk assessment } \\
\text { using CRUSADE } \\
\text { Mean CRUSADE score }\end{array}$ & 934 & 934 & $208(22.3)$ & $24.7(S D=14.0)$ \\
\hline 4.Antithrombotic during hospitalisation & & & & 79.1 \\
\hline $\begin{array}{l}\text { QI 4.1. Number of patients eligible for in-hospital antithrombotic therapies who received } \\
\geq 1 \text { therapies. }\end{array}$ & 934 & 934 & $930(99.6)$ & $738(79.4) 0.01$ \\
\hline QI 4.3. Dual antiplatelet therapy & 934 & 934 & $934(100)$ & $736(78.8) 0.01$ \\
\hline 5. Secondary prevention discharge treatment. & & & & 87.9 \\
\hline QI 5.1. Proportion of patients with AMI discharged on statins, unless contraindicated & 934 & 829 & $829(100)$ & $729(87.9) 0.01$ \\
\hline 6. Patient experience collected in a systematic way (Seattle Angina and EQ5DL). & & & & $551(76.1)$ \\
\hline Mean patient satisfaction (range 1-100) & 934 & 724 & 551 & $75.5(S D=14.00)$ \\
\hline QI 6.1. Pain reported as a symptom (EQ5DL) & 934 & 724 & $551(76.1)$ & $203(36.8) 0.02$ \\
\hline 7. Composite quality indicator (mean) & 934 & 571 & & 44 \\
\hline QI 7.3. 30-day mortality rate adjusted for GRACE 2.0 & 934 & 571 & & $0.4(0.07)$ \\
\hline
\end{tabular}

Compliance for domains 2-7 is described below. Domain 1 includes descriptive information, which is described within the main body of the results. Compliance for each indicator is reported as a proportion (\%) with the SE where appropriate. The composite proportion of compliance for each domain is in bold.

*STEMI- ST- elevation myocardial infarction. NSTEMI- non- ST- elevation myocardial infarction. EQ5D-L- EuroQual 5 domains- long.

AMI, acute myocardial infarction; ESC, European Society of Cardiology; GRACE, Global Registry of Acute Coronary Events; PCI, percutaneous coronary intervention; QI, quality indicator.

seven domains: (1) centre organisation, (2) reperfusion invasive strategy; (3) in-hospital risk assessment; (4) antithrombotics during hospitalisation; (5) secondary prevention at discharge ; (6) patient satisfaction and (7) a composite measure of care quality (table 1). The ESC guidelines include 12 indicators which together measure the structures processes and outcomes measures of high quality AMI care. 121314

\section{Data collection}

This study uses a recently implemented electronic AMI registry, codesigned by clinicians of the Sri Lanka STEMI Forum, with the purpose of enabling prospective systematic evaluation of care for patients with AMI. Using the Network for Improving Critical care Systems and Training (NICST) methodology, the registry uses a mobile platform with capacity for real-time visualisation of routine information (including referral, diagnosis and management). ${ }^{510}$ The same platform facilitates evaluation of patient-reported outcomes: satisfaction, functional recovery and burden of symptoms following discharge.

Information pertaining to patient presentation, diagnosis, management and in-hospital outcomes for all AMI admissions were prospectively captured through the registry's m-Health portal by a trained departmental research assistant. Data completeness and quality was reviewed by the research team through the registry's real-time dashboard. Patients' perspectives regarding outcomes, functional recovery, ongoing symptoms and satisfaction after discharge were collected via telephone-administered patient interviews by trained research assistants. Information regarding centre organisation of AMI care $^{11}$ was assessed by a review of administrative documentation, supplemented by information provided by the head of the department.

\section{Analysis}

Patient demographics, clinical presentation, investigations, provision of ESC recommended therapies and in-hospital events were described using descriptive statistical measures. Compliance with domain 1 (information regarding centre organisation and the presence of departmental guidelines) were described. Patients were assessed for eligibility for each of the 12 QI's according to their presenting diagnosis and prognostic group using covariates from the Global Registry of Acute Coronary Events (GRACE) Risk Model. Indicators of AMI care processes (eg, time to recognition and intervention) alongside indicators of treatment choice and availability were calculated as per the ESC guidelines. ${ }^{111516}$ Compliance was reported as a percentage of the eligible population. ${ }^{11}$ For domain 5 (secondary prevention discharge treatment), compliance with prescription of high-intensity statins at discharge was calculated. Use of $\mathrm{ACE}_{\mathrm{i}}$ inhibitors and $\beta$-blockers, routinely available in this setting (optional indicators in this domain), was not reported. For domain 6 (patient satisfaction) the Seattle Angina Questionnaire (SAQ) which includes measures of functional recovery and symptom burden was used. ${ }^{1314}$ The composite QI (CQI, domain 
7) was derived from the mean compliance of domains 1-6. The GRACE Risk Model for predicted probability of mortality, and scores for risk of bleeding complication (CRUSADE) and severity of heart failure (Killip classification) were calculated as described previously. ${ }^{17-19}$ Similarly, Likert scale responses to the SAQ and EuroQol-5 domain- long (EQ5DL) were reported according to published methods. ${ }^{13} 14$ STATA V.11.0 statistical program was used for statistical analysis.

\section{Setting}

This evaluation comes from the National Hospital of Sri Lanka, the largest PCI-capable tertiary referral centre nationally and the country's only centre with 24 hour primary PCI service.

\section{RESULTS}

\section{Demographics, risk factors and clinical presentation}

Between March 2017 and April 2018, 934 patients with AMI presented to the cardiology department. The majority of patients $844 / 934(90.4 \%)$ admitted through the registry presented with features of STEMI. The mean age of patients was 54.1 years $( \pm 12.0)$ and 791 (84.7\%) were male. On admission 174 (18.6\%) patients had a Killip classification of heart failure of $>1$. Clinical presentation and the prevalence of comorbidities and other risk factors for AMI are described in online supplementary table 1.

\section{Evaluation of quality of care}

Mean (SD) overall compliance with the CQI (domain 7) was $44 \%$ (0.07). Compliance of $\geq 50 \%$ with the CQI was achieved in $9.8 \%$ of STEMI patients. The highest compliance was observed for domains 4 and 6: antithrombotics during hospitalisation (79.1\%) and patient satisfaction (76.1\%). The lowest compliance was observed for domains describing organisational structure and process of care: $(22.4 \%)$ (table 1$)$. Thirty-day mortality following discharge was $11.9 \%$. Adjusted mortality using the GRACE score at 30 days following discharge was 10.3\%. (QI 7.3).Compliance with individual QI for each of the six domains measured is described below.

\section{Domain 1: centre organisation and system level structures of AMI care}

The four aspects of centre organisation for AMI care as described by the ESC guidelines revealed limitations in the availability of these system level structures and processes. The head of the department reported absence of a centralised referral system or single telephone number for patients presenting with AMI in Sri Lanka and absence of an organisational guideline for direct referral or transfer to this tertiary centre for primary reperfusion therap. In addition, access to prehospital ECG for diagnosis and treatment decision making is not universally available. Similarly, there was no provision for the prehospital activation of intervention services and finally, no publicly available alternative to road transportation for patients requiring PCI intervention from greater distance currently exists in the region. Routes to admission for patients with symptoms of AMI vary, including via acute medical wards and an emergency treatment unit in addition to direct admission to the cardiology department. Clinicians communicate referrals through personal phones to cardiology in the absence of designated facility-level services. Access to road transportation for patients presenting both as a referral from another healthcare facility and directly to the PCI centre is described in online supplementary table 2. A minority of 16 (7.1\%) patients presenting directly to the PCI facility arrived by

\begin{tabular}{|c|c|c|c|c|}
\hline $\begin{array}{l}\text { Characteristics } \\
N(\%)\end{array}$ & $\mathrm{N}$ & AMI 934 & $\begin{array}{l}\text { STEMI } \\
844 \text { (90.4) }\end{array}$ & $\begin{array}{l}\text { Non-STEMI } \\
90(9.6)\end{array}$ \\
\hline \multicolumn{5}{|l|}{ Demographics } \\
\hline Gender, male, $N(\%)$ & 934 & $791(84.7)$ & $732(86.7)$ & $59(65.6)$ \\
\hline Age, years & 928 & $54.1 \pm 12.0$ & $53.6 \pm 11.9$ & $58.5 \pm 12.4$ \\
\hline Killip class >i & 934 & $174(18.6)$ & $148(17.5)$ & $26(28.9)$ \\
\hline Killip class >iii & & $149(15.9)$ & $126(14.9)$ & $23(25.6)$ \\
\hline In-hospital mortality & 900 & & & \\
\hline Dead & & $71(7.9)$ & $66(7.8)$ & $5(5.6)$ \\
\hline Not recorded & & 34 & 33 & 1 \\
\hline 30-day mortality & 827 & & & \\
\hline Dead & & $98(11.9)$ & $91(12.1)$ & $7(9.1)$ \\
\hline Not recorded & & 107 & 94 & 13 \\
\hline \multicolumn{5}{|l|}{ Length of stay in days } \\
\hline $\begin{array}{l}\text { Mean (SD), median } \\
\text { (IQR) }\end{array}$ & 822 & $6.5(6.4), 4(4)$ & $6.2(6.0), 4(4)$ & $8.7(9.2), 5$ (4) \\
\hline
\end{tabular}

ambulance, whereas (91.1\%) patients arrived by private or hired vehicle.

Regarding the secondary QI for domain 1 (QI 1.2 and 1.3), $488(58.1 \%)$ of all STEMI patients underwent a primary reperfusion intervention (either PCI or thrombolysis). Primary percutaneous coronary intervention was performed in 435 (51.8\%) of all STEMI patients (table 2).

\section{Domain 2: reperfusion invasive strategy}

In patients admitted with STEMI, 442 (53.0\%) underwent PCI within the first 12 hours of admission to the tertiary PCI facility. Of the 53 STEMI patients who received a fibrinolytic agent as their primary reperfusion strategy, $10(25.6 \%)$ were treated within 30 mins of admission (QI 2.1). Median (IQR) door-toneedle time was $60 \mathrm{~min}$ (111.1). A total of $45(14.6 \%)$ patients underwent primary PCI within $60 \mathrm{~min}$, and the median (IQR) 'door to balloon time' was $118.1 \mathrm{~min}$ (116.8) (QI 2.2). Of those patients who were diagnosed as having NSTEMI, and with no identified contraindication, 27 (30\%) received coronary angiography within 72 hours of admission (QI 2.3).

\section{Domain 3: in-hospital risk assessment}

In patients presenting with NSTEMI, 71 (78.9\%) had a calculation of the GRACE score on admission (QI 3.1) (online supplementary table 3). Mean (SD) GRACE score in this population was 120 (40), translating to a predictive mean probability of death at hospital discharge of $1 \%-3 \%$. The majority of patients $(71.8 \%)$ had a low or intermediate predicted risk of death. A GRACE score was available for $78.9 \%$ of patients with a NSTEMI. In these patients, the actual in-hospital mortality was $7.0 \%$ (online supplementary table 5). In the remaining 19 patients without complete variables available for the GRACE score, actual mortality was 0 . Variables enabling calculation of the CRUSADE score were available in only $22.2 \%$ of patients (QI 3.2). Mean (SD) probability of post-Myocardial Infarction (MI) bleeding risk was 24.7 (14), indicating a low risk of bleeding (table 1).

\section{Domain 4: antithrombotic treatment during hospitalisation}

A total of $930(99.6 \%)$ inpatients were eligible for antithrombotic therapy. Of these, $738(79.5 \%)$ patients received at discharge a prescription of a $\mathrm{P}_{2} \mathrm{Y}_{12}$ inhibitor (Prasugrel or Ticagrelor or clopidogrel) (QI 4.1), whereas 736 (78.8\%) were prescribed 


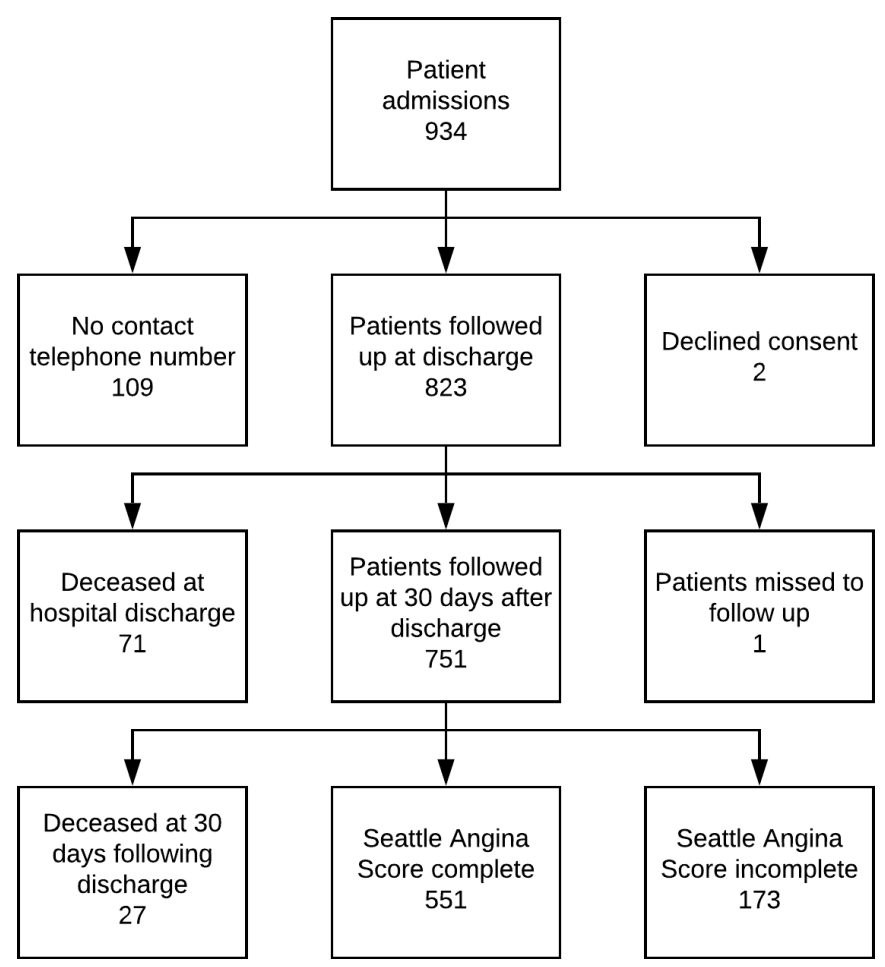

Figure 1 Patients recruited through the PROTECT AMI platform to systematic follow-up at 30 days following discharge.

dual antiplatelet therapy (aspirin plus a $\mathrm{P} 2 \mathrm{Y}_{12}$ inhibitor) (QI 4.3). Criteria for fondaparinux administration were met by 90 patients (QI 4.2); however, this drug was not available during the evaluation period.

\section{Domain 5: secondary prevention discharge treatment}

A total of 829 patients were eligible for high-intensity statins on discharge. Of these, 729 (87.9\%) patients were reported as having this prescribed at discharge (QI 5.1).

\section{Domain 6: systematic measurement of patient satisfaction and symptom burden}

A total of 829 (92.1\%) patients were discharged alive, of which $751(90.6 \%)$ patients were followed up at 30 days following discharge figure 1. At 30 days following discharge, 724 (96.4\%) patients were alive, of whom 551 (73.4\%) were interviewed for satisfaction with care, functional recovery and burden of symptoms (Figure 1). Mean (SD) score for physical limitation was 84.3 (22) with 512 (92.9\%) of patients reporting minimal-to mild limitations. Ongoing symptoms of pain and discomfort were reported by $34.89 \%$ of the STEMI population. Of those patients who underwent PCI, 98.2\% patients reported that their symptoms of angina were 'somewhat' or 'much better' 30 days following discharge (online supplementary table 4). In addition, 448 (81.3\%) patients reported having access to cardiology services following discharge. Mean patient satisfaction score reported by patients with STEMI was 76.0 (SD 13.9) (range 0-100), with $333(67.6 \%)$ STEMI and 26 (44.8\%) of NSTEMI were 'completely satisfied' with their treatment (QI 6.1).

\section{DISCUSSION}

This study provides a continuous evaluation of the quality of AMI care including patient centred outcomes from an LMIC. It provides detailed information on the organisational structures and processes that influence patients' outcomes providing both a benchmark of the quality of care, and detailed information through which those responsible for AMI and coronary vessel disease (CVD) care can evaluate previous investments and focus future improvements to reduce mortality and morbidity.

Structural improvements in diagnostic and interventional services are evident at this PCI-capable tertiary care centre in Sri Lanka. Over 50\% of patients eligible for reperfusion therapy received treatment within 12 hours of admission, and nearly three-quarters $(72.0 \%)$ of patients diagnosed with a STEMI underwent PCI. These numbers are higher than previously reported in Sri Lanka and may positively reflect the impact of recent investments in hospital services by the Ministry of Health, such as making stents available for free at PCI centres since 2018. ${ }^{5}$ 20-22 Antiplatelet therapies and high-intensity statins essential to reducing mortality in the AMI population were administered in over $75 \%$ and nearly $90 \%$ of all eligible patients, respectively (domains 4 and 5). These are improvements on previous, smaller evaluations at the same centre ${ }^{23}$ and are comparable with benchmarks of quality from the UK and Europe, and higher than cited in neighbouring South Asian countries. ${ }^{15} 2024$ Similarly, the timely availability of physiological and biochemical information for risk stratification is encouraging. The utilisation of such tools in front-line clinical care is reflective of an evidence-based approach to medicine and of a notable improvement in the availability of laboratory and point of care testing, the absence of which so often underlies the failure to apply risk stratification tools for acutely unwell patients in resource-limited settings. ${ }^{1021}$

Patient-reported measures of outcome and satisfaction are central to understanding the quality of care and directing future improvements to achieve universal healthcare. It must be acknowledged, however, that patient perspectives of quality and priorities for recovery may well be different depending on the setting, population demographics and the social capital of patients and their families. In this systematic evaluation of symptoms and recovery, one-fifth of patients were still reporting symptoms of pain and discomfort, limitations in routine activities of daily life (eg, personal care) and in physical recovery at 30 days following discharge from hospital. While ongoing symptoms up to 1 year following invasive intervention for STEMI are frequently described in the literature, limitation in functional capacity is a significant finding in this relatively young, working age, predominantly male population. ${ }^{16}$ Delays in recovery and ongoing burden of symptoms may be compounded by the paucity of access to both cardiac rehabilitation and more generalised ambulatory rehabilitation services in the region. ${ }^{25}$

Despite an ongoing daily burden of symptoms reported by patients, overall reported satisfaction was good (mean 75.5, SD 14.0). This seemingly high level of satisfaction requires further exploration; there is limited understanding of the cultural variation in patients' ability to interpret and describe satisfaction within different societies. Work undertaken in settings where access to healthcare is scarce suggests that patients satisfaction is multidimensional and is influenced by the caregiver-patient relationship, the environment of healthcare provision and economic factors including direct and indirect costs of healthcare. ${ }^{26}$ Patients in this setting may, for example, report higher than expected levels of satisfaction when healthcare is offered free or when treatments (such as PCI), for which they would previously have paid, have become newly available. Similarly, in Sri Lanka, where doctors of western medicine are revered highly within the community, patients may feel compelled to give positive responses. Further work to understand both patients' 
Key messages

\section{What is already known on this subject?}

- Recent high profile publications, ${ }^{122}$ in this and other international journals, have highlighted the impact that poor quality of care is having on outcomes globally, and specifically, the excess mortality and morbidity associated to poor quality of care for cardiovascular disease in South Asia. However, as highlighted by an editorial in this journal and more recently in a review again earlier this year, ${ }^{1022}$ the existing quality of care and the impact of these investments on patient recovery remain absent. Efforts to evaluate care in the region have been hampered by sampling and limited to in hospital care. ${ }^{10}$

\section{What might this study add?}

- This evaluation in the South Asian region uses international quality indicators including processes of prehospital care, measures of patient recovery and outcomes at 30 days following hospital discharge. For the wider cardiology community internationally, it provides a practical method for establishing quality evaluation as part of routine care that is feasible even in resource-limited health systems.

\section{How might this impact on clinical practice?}

- This work provides an objective assessment from which specific recommendations for future improvement in acute myocardial infarction (AMI) services can be compared against. Recommendations from this evaluation, specifically the clinician-led restructuring of departmental patient flow ${ }^{30}$ and the establishment of a hub and spoke network for AMI care to help rationalise the use of pharmaco-invasive interventions for patients facing delays in accessing primary percutaneous coronary intervention, are currently under development.

perspectives and behaviours that influence patient expectation and experience is required.

The greatest opportunities to improve quality of AMI care are within the delivery (processes) and organisation of care. 'Time to delivery' of definitive interventions such as fibrinolytics and primary PCI was considerably longer than the ESC guidelines. ${ }^{11}$ Inefficiencies and delays in the delivery of in-hospital intervention and in the pathways related to accessing AMI services mirror barriers identified in a recent review of AMI care in LMICs. ${ }^{42327}$ The absence of prehospital services and bottlenecks in prehospital activation of interventional services, which includes assembling skilled clinicians and preparation of equipments, may further account for the higher than predicted mortality in this STEMI population. ${ }^{11}{ }^{28}$ Despite the recent provision of ambulance service in the region, very few patients used the service when presenting to the tertiary facility from the community. The impact of pre-hospital access on 'time to intervention' is not explored within this evaluation. ${ }^{22}$

Overcoming the barriers and bottlenecks to efficient organisational delivery of AMI care (both structure and process) is fundamental to improving the quality of care. ${ }^{29}$ Work already published by the authors as part of a health systems improvement network have highlighted additional bottlenecks in organisational structure, process and patient-centred- in care. ${ }^{29}$ Focus groups held with frontline healthcare workers to map the pathways of AMI care revealed that diagnosis of
AMI was delayed due to inconsistencies in patients' timeliness of presentation, accessibility of ECG investigation for patients when presenting with the symptoms of syndromic acute coronary syndrome and delays in reporting of ECG. These delays resulted in bottlenecks to accessing expert cardiology services. ${ }^{226}$ In response to this, a project is underway by the authors to explore how the m-Health platform used here for the registry might help provide a solution to the organisational aspects of delay. Adaptation of the application to enable a digital referral pathway between PCI and non-PCI capable cardiology centres and to enable direct designated communication between medics in the emergency admission unit and the on-call cardiologists is underway. Similar interventions, which have sought to network primary and secondary services around a central PCI centre and to prioritise pharmacoinvasive interventions in the absence of revascularisation services have successfully reduced mortality in India and other LMIC settings. ${ }^{22}$

The Sri Lanka STEMI Forum's registry is now live in four tertiary hospitals that serve the highly populated western and northern provinces. Work is now underway to evaluate how prehospital systems and human factors not explored here may impact on clinical endpoints, such as clinician decision making following risk assessment, patient adherence to medication and time from first medical contact to intervention. ${ }^{1028}$

\section{CONCLUSION}

This evaluation provides new patient-centred insights into the existing quality of care. Barriers to the delivery of high-quality AMI appear common to those in other LMICs. Clear priorities for investment include improved prehospital care, networking of primary and secondary facilities with PCI capable centres and streamlined in-hospital referral and treatment. Patient-reported measures including outcome and satisfaction are central to understanding the quality of care and directing future improvements to achieve universal healthcare.

Correction notice Since this article was first published online, the first two authors have switched positions and the paper has been made open access.

Twitter Rashan Haniffa @rhaniffa

Acknowledgements We would like to acknowledge the collaborators for their clinical intellectual contributions and the families and patients that provided important insights into their experiences of AMI care.

Collaborators Santharaj WS, Mendis SAES, Fernando N, Fernando KMTM, Galappaththi G, Amarasekara HSU, Rajakanthan K, Rajapakse GSS, Silva APD.

Funding This study was funded by Network for Improving Critical Care System and Training and the Sri Lanka STEMI forum as part of ongoing projects to improve the quality of acute care.

\section{Competing interests None declared.}

Patient consent for publication Not required.

Ethics approval Ethical approval for the study was obtained from the Colombo Research and Ethics committee (EC-17-059).

Provenance and peer review Not commissioned; externally peer reviewed. Data availability statement Data are available upon reasonable request.

Open access This is an open access article distributed in accordance with the Creative Commons Attribution Non Commercial (CC BY-NC 4.0) license, which permits others to distribute, remix, adapt, build upon this work non-commercially, and license their derivative works on different terms, provided the original work is properly cited, appropriate credit is given, any changes made indicated, and the use is non-commercial. See: http://creativecommons.org/licenses/by-nc/4.0/.

ORCID iD

Abi Beane http://orcid.org/0000-0001-7046-1580 


\section{REFERENCES}

1 Kruk ME, Gage AD, Joseph NT, et al. Mortality due to low-quality health systems in the universal health coverage era: a systematic analysis of amenable deaths in 137 countries. The Lancet 2018;392:2203-12.

2 Huber K, Gersh BJ, Goldstein P, et al. The organization, function, and outcomes of STelevation myocardial infarction networks worldwide: current state, unmet needs and future directions. Eur Heart J 2014;35:1526-32.

3 Lodi-Junqueira L, Ribeiro AL. Tackling acute coronary syndrome in low-income and middle-income countries. Heart 2018;104:1390-1.

4 Galappatthy P, Bataduwaarachchi VR, Ranasinghe P, et al. Management, characteristics and outcomes of patients with acute coronary syndrome in Sri Lanka. Heart 2018;104:1424-31.

5 Sri Lanka department of health, annual health Bulletin, 2012. Available: http://www. health.gov.lk/ [Accessed 3 Oct 2018].

6 Belgian Interdisciplinary Working Group on Acute Cardiology. Stemi project: quality control project in ST elevation myocardial infarction; 2017.

7 European Society of Cardiology. Acute coronary syndrome STEMI (ACS) registry; 2008

8 Zampieri FG, Soares M, Borges LP, et al. The Epimed monitor ICU Database $®$ : a cloudbased national Registry for adult intensive care unit patients in BrazilEpimed monitor ICU Database $\circledR$ : Um registro nacional baseado Na nuvem, para pacientes adultos internados em unidades de terapia intensiva do Brasil. Revista Brasileira de terapia intensiva 2017:29:418-26.

9 Haniffa R, De Silva AP, Beane A, et al. A cloud-based national critical care registry - a South Asian LMIC data platform. Brazilian Journal of Intensive care ahead of print.

10 Beane A, De Silva AP, Athapattu PL, et al. Addressing the information deficit in global health: lessons from a digital acute care platform in Sri Lanka. BMJ Glob Health 2019;4:e001134.

11 Ibanez B, James S, Agewall S, et al. 2017 ESC guidelines for the management of acute myocardial infarction in patients presenting with ST-segment elevation: the task force for the management of acute myocardial infarction in patients presenting with ST-segment elevation of the European Society of cardiology (ESC). Eur Heart J 2018;39:119-77.

12 Donabedian A. Evaluating the quality of medical care. Milbank Mem Fund Q 1966:44:166-206.

13 Balestroni G, Bertolotti G. [EuroQol-5D (EQ-5D): an instrument for measuring quality of life]. Monaldi Arch Chest Dis 2012;78:155-9.

14 Spertus JA, Winder JA, Dewhurst TA, et al. Development and evaluation of the Seattle angina questionnaire: a new functional status measure for coronary artery disease. $J$ Am Coll Cardiol 1995;25:333-41.

15 Schiele F, Gale CP, Bonnefoy E, et al. Quality indicators for acute myocardial infarction: a position paper of the acute cardiovascular care association. Eur Heart J Acute Cardiovasc Care 2017:6:34-59.
16 Bonow RO, Masoudi FA, Rumsfeld IS, et al. ACC/AHA classification of care metrics: performance measures and quality metrics: a report of the American College of Cardiology/American heart association Task force on performance measures. J Am Coll Cardiol 2008:52:2113-7.

17 Fox KAA, Fitzgerald G, Puymirat E, et al. Should patients with acute coronary disease be stratified for management according to their risk? derivation, external validation and outcomes using the updated grace risk score. BMJ Open 2014;4:e004425.

18 Killip T, Kimball JT. Treatment of myocardial infarction in a coronary care unit. A two year experience with 250 patients. Am J Cardiol 1967;20:457-64.

19 Subherwal S, Bach RG, Chen AY, et al. Baseline risk of major bleeding in non-STsegment-elevation myocardial infarction: the crusade (can rapid risk stratification of unstable angina patients suppress adverse outcomes with early implementation of the ACC/AHA guidelines) bleeding score. Circulation 2009;119:1873-82.

20 Rosengren A, Wallentin L, Simoons M, et al. Age, clinical presentation, and outcome of acute coronary syndromes in the Euroheart acute coronary syndrome survey. Eur Heart J 2006;27:789-95.

21 Haniffa R, Pubudu De Silva A, Weerathunga P, et al. Applicability of the APACHE II model to a lower middle income country. J Crit Care 2017;42:178-83.

22 Nascimento BR, Brant LCC, Marino BCA, et al. Implementing myocardial infarction systems of care in low/middle-income countries. Heart 2019;105:20-6.

23 Rahuman MBF, Jayawardana JB, Francis GR, et al. Outcome of early coronary intervention for acute ST elevation myocardial infarction in a tertiary care cardiac centre in Sri Lanka. Ceylon Med J 2016;61:26-31.

24 Rosselló X, Huo Y, Pocock S, et al. Global geographical variations in ST-segment elevation myocardial infarction management and post-discharge mortality. Int $J$ Cardiol 2017:245:27-34.

25 Sigera PC, Tunpattu TMUS, Jayashantha TP, et al. National profile of physical therapists in critical care units of Sri Lanka: lower middle-income country. Phys Ther 2016;96:933-9.

26 Dagger TS, Sweeney JC, Johnson LW. A hierarchical model of health service quality: scale development and investigation of an integrated model. J Serv Res 2007; 10:123-42

27 Mohanan PP, Mathew R, Harikrishnan S, et al. Presentation, management, and outcomes of 25748 acute coronary syndrome admissions in Kerala, India: results from the Kerala ACS registry. Eur Heart J 2013:34:121-9.

28 Lana MLL, Beaton AZ, Brant LCC, et al. Factors associated with compliance to AHA/ ACC performance measures in a myocardial infarction system of care in Brazil. Int J Qual Health Care 2017;29:499-506.

29 Beane A, Wagstaff D, Abayadeera A, et al. A learning health systems approach to improving the quality of care for patients in South Asia. Glob Health Action 2019;12:1587893

30 Haniffa R, Pubudu De Silva A, de Azevedo L, et al. Improving ICU services in resourcelimited settings: perceptions of ICU workers from low-middle-, and high-income countries. J Crit Care 2018:44:352-6. 